\title{
A CARACTERIZAÇÃO DE DANO AMBIENTAL E SUA COMPLEXIDADE
}

\author{
Rosa Maria Guimarães Alves ${ }^{1}$ \\ Shirley Oliveira Lima Nomura ${ }^{2}$ \\ Elias Manea ${ }^{3}$
}

RESUMO: A degradação ocorrida na natureza não é um fato recente, pois em toda história conhecida da humanidade se comprova que, os interesses pessoais se colocam no primeiro plano, em detrimento aos danos causados ao meio ambiente. O maior dilema é a caracterização do que é o dano ambiental, pois seus reflexos atingem tanto o sistema financeiro, quanto a qualidade de vida e bem estar, individual e coletivo da sociedade atual. Por isso a necessidade de se adequar ao modelo do desenvolvimento ecologicamente sustentável se torna mais urgente, conforme aumenta os danos ambientais. Neste estudo, serão abordadas algumas definições doutrinárias e as legislações constitucionais dos direitos fundamentais de terceira geração, o qual está inserido a proteção ao Meio Ambiente, e suas ramificações nos direitos fundamentais de primeira e segunda geração, sem entrar no mérito das legislações específicas, que será objeto de estudo posterior. O objetivo é demonstrar aos leitores, a complexidade existente na configuração do que é Dano Ambiental, e as possíveis consequências jurídicas advindas deste ato ilícito, para a posterior reflexão sobre os efeitos que advirão no bem

\footnotetext{
${ }^{1}$ Docente do curso de Direito da UNOESTE - Presidente Prudente-SP, Procuradora do Estado e Mestre em Direito Processual Civil pela Universidade do Oeste Paulista-SP. E-mail: rmgalves07@yahoo.com.br ${ }^{2}$ Docente do curso de Direito da UNOESTE - Presidente Prudente-SP - Mestre em Direito Político e Econômico pela Universidade Mackenzie-SP. E-mail: sholiveiralima@gmail.com.br

${ }^{3}$ Discente do curso de Direito da UNOESTE, Presidente Prudente - SP. E-mail: manea_ppt@hotmail.com
} 
estar material, mental, físico e social do indivíduo e, consequentemente, de toda a coletividade.

Palavras-chaves: Dano ambiental. Legislação. Meio Ambiente.

\section{INTRODUÇÃO}

É interessante refletir como despontaram os problemas ambientais. A socióloga Rita Mendonça ${ }^{4}$ diz que, segundo os biólogos chilenos Humberto Maturana e Francisco Valera, bem como a historiadora austríaca Rione Cisler, os problemas ambientais, surgiram há 7 (sete) mil anos, com o fim da cultura matrística. Esta cultura é traduzida pelo domínio da mulher sobre a sociedade da época e, nela, a relação com a natureza e com as pessoas era caracterizada por limites e estabelecida de forma harmônica e as pessoas eram parte do ambiente. Havia, por isso, perfeito entrosamento, integração dos povos daquela época com o meio ambiente.

No entanto, substituída pela cultura patriarcal, o homem (com objetivos diversos da mulher), desejava o domínio de outros povos e, mesmo, do meio no qual viviam. ${ }^{5}$

A partir de então, as conquistas de terras foram integrando a realidade daqueles tempos e, nessa caminhada, foi surgindo o desenvolvimento que, no século passado, alcançou elevado destaque, chegando às raias do desenvolvimento desenfreado.

Em contrapartida, evidenciaram-se os efeitos adversos do desenvolvimento a qualquer custo e, a tragédia de Chernobyl, as diferenças no clima, o aquecimento global, o deslocamento do eixo da terra e o efeito estufa, apenas para citar alguns casos, alertaram a humanidade e a levaram à consciência que era necessário pensar nas causas

\footnotetext{
${ }^{4}$ Rita Mendonça é escritora e publica as obras "Conservar e Criar - Natureza, Cultura e Complexidade". Ed. Senac e "A Sombra das Árvores - Transdiciplinariedade e Educação Ambiental em Atitudes Extraclasse", este em autoria com Zysman Neimar - Ed. Chronos.

${ }^{5}$ Citada por Rita Mendonça, bióloga e socióloga, na entrevista "O educador ambiental ensina por suas atitudes".
} 
responsáveis por estes fatos. Foi quando eclodiu a ideia da sustentabilidade mas, como ela colidia frontalmente com o desenvolvimento, o pensar levou à ideia do desenvolvimento sustentável. Esta é a tônica dos dias atuais e, pode-se afirmar que se não atentar para o desenvolvimento sustentável, as degradações das condições de vida no planeta ficarão cada vez pior, quiçá até mesmo insuportáveis.

Por isso, surgiu a consciência ecológica e, enquanto ela não integrar toda a sociedade mundial, há que se cuidar das consequências nefastas do desenvolvimento, por ora traduzidas na expressão dano ambiental.

É disso que o artigo tratará, conforme segue.

\section{O DANO AMBIENTAL}

O dano ambiental é de difícil conceituação. Tal ocorre porque o tema Meio Ambiente é amplo, difuso, abrange vários aspectos. Neste passo, pode-se afirmar a característica multidimensional, multifacetária do meio ambiente. Aliás, considerado como direito de terceira dimensão, não há como negar que ele abrange os direitos de primeira dimensão (direitos civis e políticos ou as liberdades clássicas), os de segunda (direitos econômicos, sociais e culturais) e, perfeitamente amoldado ao princípio da solidariedade humana, ganha dimensão ímpar e caracteriza-se pela sua inexauribilidade.

Por oportuno, transcreve-se lição de Helita Barreira Custório, inserida na tese "Autonomia do Município na Preservação Ambiental". pp 1 e ss 2:

Para os fins protecionais, a noção de meio ambiente é muito ampla, abrangendo todos os bens naturais, sociais, artificiais e culturais de valor juridicamente protegido, desde o solo, as águas (superficiais e subterrâneas), o ar, a flora, a fauna, as belezas naturais e artificiais, a pessoa humana ao patrimônio histórico, artístico, turístico, paisagístico, monumental, arqueológico, além das variadas disciplinas urbanísticas hodiernas. 
Por estes motivos, o dano ambiental, seguindo nesse compasso, não se coaduna somente com o dano tratado pelo direito civil ou outros danos do ordenamento jurídico brasileiro: ele é uma espécie de tertium genus de dano.

De outra parte, o texto constitucional prescreve que as condutas e atividades consideradas lesivas ao meio ambiente sujeitarão os infratores, pessoas físicas ou jurídicas, a sanções penais e administrativas, independentemente da obrigação de reparar os danos causados. As sanções administrativas e penais estão previstas na Lei 9.605/98 que dispõe sobre as sanções penais e administrativas derivadas de condutas e atividades lesivas ao meio ambiente Outrossim, a Lei 6.938/81, traz sanções de ordem administrativa ao causador do dano, como, por exemplo, a perda ou restrição de incentivos e benefícios concedidos pelo Poder Público.

Porém, estas sanções não serão objeto deste trabalho: o que se busca é identificar o dano ambiental, esta espécie de terceiro gênero de dano, ainda não prevista adequadamente no ordenamento jurídico brasileiro, porque de difícil definição.

O doutrinador Leite (2003), assim o caracteriza:

O dano ambiental constitui uma expressão ambivalente, que designa, certas vezes, alterações nocivas ao meio ambiente e outras, ainda, os efeitos que tal alteração provoca na saúde das pessoas e em seus interesses. Dano ambiental significa, em uma primeira acepção, uma alteração indesejável ao conjunto de elementos chamados meio ambiente, como, por exemplo, a poluição atmosférica; seria, assim, a lesão ao direito fundamental que todos têm de gozar e aproveitar do meio ambiente apropriado. Contudo, em sua segunda conceituação, dano ambiental engloba os efeitos que esta modificação gera na saúde das pessoas e seus interesses.

Por seu turno, Carvalho(2008) afirma que apesar de não existir um conceito legal aliado à uma construção doutrinária e jurisprudencial do que seria dano ambiental é possível chegar-se a uma conclusão por meio da legislação. Neste caso, a Lei no 6.938/81, que, ao tratar da degradação, da qualidade ambiental e poluição, prevê o seguinte:

Art $3^{\circ}-$ Para os fins previstos nesta Lei, entende-se por: 
$[\ldots]$

II - degradação da qualidade ambiental, a alteração adversa das características do meio ambiente.

III - poluição, a degradação da qualidade ambiental resultante de atividades que direta ou indiretamente:

a) prejudiquem a saúde, a segurança e o bem-estar da população;

b) criem condições adversas às atividades sociais e econômicas;

c) afetem desfavoravelmente a biota;

d) afetem as condições estéticas ou sanitárias do meio ambiente;

e) lancem matérias ou energia em desacordo com os padrões ambientais estabelecidos;

Esta classificação indica que o dano pode ter indenização direta, quando diz respeito a interesses individuais e, pode ter indenização indireta, quando diz respeito à interesses difusos, coletivos e, eventualmente, individuais e coletivos.

Ainda seguindo a preleção de Leite (2003), o dano ambiental pode ser detectado pela amplitude do bem protegido e quanto à sua extensão. Destarte, classifica-o da seguinte maneira:

Quanto a amplitude do bem protegido:

a) dano ecológico puro, sendo aquele que atinge, de forma intensa, bens próprios da natureza, em sentido estrito, não se relacionando com os componentes do patrimônio cultural ou artificial;

b) dano ambiental lato sensu relacionado aos interesses difusos da coletividade, abrangendo todos os componentes do meio ambiente;

c) dano ambiental individual ou reflexo, conectado ao meio ambiente, visando à tutela de interesses individuais ou coletivos.

Quanto à sua extensão:

a) dano patrimonial ambiental, relativamente à restituição, recuperação ou indenização do bem ambiental lesado;

b) dano extrapatrimonial ou moral ambiental quando diz respeito à sensação de dor experimentada ou conceito equivalente em seu mais amplo significado ou todo prejuízo não patrimonial ocasionado à sociedade ou ao indivíduo, em virtude de lesão ao meio ambiente. 
Estudadas as facetas que podem assumir o dano ambiental, vejamos alguns outros conceitos relacionados ao dano ambiental, levando-se em consideração a pessoa ou pessoas atingidas pelo dano ambiental, bem como a sua incidência sobre o bem atingido.

A Lei 6.938/81, em seu art. 14, §1ํㅡ, prevê expressamente duas modalidades de dano ambiental ao referir-se a "danos causados ao meio ambiente e a terceiros", ou seja, de acordo com o destinatário do bem lesado.

Esta lei está em perfeita consonância com o disposto no art. 225 , § 3od da Constituição Federal, in verbis:

As condutas e atividades consideradas lesivas ao meio ambiente sujeitarão os infratores, pessoas físicas ou jurídicas, a sanções penas e administrativas, independente da obrigação de reparar os danos causados.

E, 0 art. 14 da lei mencionada dispõe que:

Art. 14 - Sem prejuízo das penalidades definidas pela legislação federal, estadual e municipal, o nãocumprimento das medidas necessárias à preservação ou correção dos inconvenientes e danos causados pela degradação da qualidade ambiental sujeitará os transgressores (...).

§1ํ Sem obstar a aplicação das penalidades previstas neste artigo, é o poluidor obrigado, independentemente da existência de culpa, a indenizar ou reparar os danos causados ao meio ambiente e a terceiros, afetados por sua atividade.

Pela leitura desses dispositivos e de acordo com a melhor doutrina sobre o assunto, pode-se classificar o dano ambiental, de acordo com Piva Carvalho (2000), em:

a) Dano ambiental coletivo, dano ambiental em sentido estrito ou dano ambiental propriamente dito. Causado ao meio ambiente globalmente considerado, em sua concepção difusa, como patrimônio coletivo, atingindo um número indefinido de pessoas, sempre devendo ser, sua indenização, cobrada por Ação Civil Pública ou Ação Popular. Quando cobrada eventual indenização, é destinada a um Fundo, cujos recursos serão alocados à reconstituição dos bens lesados.

b) Dano ambiental individual ou pessoal. Viola interesses pessoais, legitimando os lesados a uma reparação pelo prejuízo patrimonial ou extrapatrimonial. Podem ser ajuizadas ações individuais, de maneira independente, não tendo as sentenças exaradas efeito de coisa julgada entre a ação individual e a coletiva. 
A Lei no 7.347 de 24 de julho de 1985 que disciplina a ação civil pública de responsabilidade por danos causados ao meio ambiente, ao consumidor, a bens e direitos de valor artístico, estético, histórico, turístico e paisagístico cria o Fundo de Defesa dos Direitos Difusos. Este Fundo foi regulamentado pelo Decreto no 1.306, de 9 de novembro 1994, criando um conselho gestor que tem como uma das suas competências, zelar pela aplicação dos recursos na consecução dos objetivos previstos na Lei 7.347/85.

Resumindo as considerações alhures, elencadas e, para melhor visualização do dano ambiental como um todo, confira-se o quadro abaixo:

Quadro 1 - Classificação do dano ambiental.

\begin{tabular}{|c|c|c|}
\hline Levando em conta & Significações & Espécie de Dano \\
\hline $\begin{array}{l}\text { 1) A amplitude do bem } \\
\text { protegido }\end{array}$ & $\begin{array}{l}\text { 1) Conceitos restrito, amplo e } \\
\text { parcial do bem ambiental }\end{array}$ & $\begin{array}{l}\text { a) dano ecológico puro (restrito); } \\
\text { b) dano ambiental(amplo); } \\
\text { c) dano ambiental individual ou reflexo } \\
\text { (parcial). }\end{array}$ \\
\hline $\begin{array}{l}\text { 2) A reparabilidade e o } \\
\text { interesse envolvido }\end{array}$ & $\begin{array}{l}\text { 2) Obrigação de reparar } \\
\text { diretamente ao interessado ou } \\
\text { indiretamente ao bem ambiental } \\
\text { protegido. Relativamente ao } \\
\text { interesse do proprietário do bem } \\
\text { (microbem), ou concernente ao } \\
\text { interesse difuso da coletividade na } \\
\text { proteção do bem ambiental } \\
\text { (microbem). }\end{array}$ & $\begin{array}{l}\text { a)dano de reparabilidade direta; } \\
\text { b)dano de reparabilidade indireta. }\end{array}$ \\
\hline 3) A extensão do dano & $\begin{array}{l}\text { 3)Considerando lesividade } \\
\text { verificada no bem ambiental }\end{array}$ & $\begin{array}{l}\text { a) dano ambiental patrimonial; } \\
\text { b) dano ambiental extra-patrimonial ou } \\
\text { moral }\end{array}$ \\
\hline $\begin{array}{l}\text { 4) Os interesses } \\
\text { objetivados }\end{array}$ & $\begin{array}{l}\text { 4) Considerando os } \\
\text { interesses objetivados na } \\
\text { tutela jurisdicional pretendida. }\end{array}$ & $\begin{array}{l}\text { a) dano ambiental de interesse da } \\
\text { coletividade; } \\
\text { b) dano ambiental de interesse subjetivo } \\
\text { fundamental; } \\
\text { c) dano ambiental de interesse individual. }\end{array}$ \\
\hline
\end{tabular}

Fonte: Leite

CONCLUSÃO 
Verificou-se que o desenvolvimento a qualquer custo gera a degradação ambiental, mas, deve-se levar em conta que o desenvolvimento econômico é fator para uma melhor qualidade de vida e que ela está diretamente relacionada com o respeito ao meio ambiente.

Tem-se, pois, um impasse: de um lado o desenvolvimento econômico e, de outro, o meio ambiente equilibrado.

Como conciliar ambos para que o desrespeito ao meio ambiente não cause o dano ambiental e, ao mesmo tempo, não frear o desenvolvimento econômico?

Conforme salienta Marcos Sorrentino et al (2005) "Ainda na década de 1970, começou-se a discutir um modelo de desenvolvimento que harmonizasse as relações econômicas com o bem-estar das sociedades e a gestão racional e responsável dos recursos naturais que Ignacy Sachs (1986) denominou de ecodesenvolvimento".

No mesmo sentido, Luis P. Sirvinkas (2003), propõe um planejamento contínuo "atendendo-se adequadamente às exigências de ambos e observando-se as suas interrelações particulares a cada contexto sociocultural, político, econômico e ecológico, dentro de uma dimensão tempo/espaço".

Porém, até que está situação ideal seja alcançada (e esforços estão sendo envidados neste sentido e, a titulo de exemplo, confira-se os eixos temáticos do IX Fórum Ambiental da Alta Paulista), há que se lidar com o dano ambiental.

Assim, surgiu a ideia do presente artigo: intentar conhecê-lo melhor. Mas, verificouse, também, a sua complexidade e sua inexauribilidade.

No entanto e a despeito destas características do dano ambiental que dificultam sua precisão, seus contornos já foram delineados e, as espécies de dano elencadas no artigo, possibilitam vislumbrá-los com mais clareza.

Resta, então, focalizar de forma mais percuciente cada um deles e, a partir daí direcionar estudo aprofundado dos bens que ele atingir. Isto implicará em tarefa mais árdua, porém necessária para conhecer os efeitos que os danos ambientais causam, e as 
formas de sua reparabilidade, ou seja, encontrar meios eficazes e aptos para minimizar e recompor a lesão ao meio ambiente.

\section{REFERÊNCIAS}

CUSTÓDIO, H.B. - Revista dos Tribunais no 652, fevereiro/1990, página 14

LEITE, J. R. M. Dano Ambiental: do individual ao coletivo extrapatrimonial. 4 ed., São Paulo: LTr, 2003.

PIVA CARVALHO, R. Bem ambiental. São Paulo: Max Limonad, 2000.

SIRVINKAS, L. P. - Manual de direito ambiental, 2 ed. São Paulo: Saraiva, 2003.

SORRENTINO, M; TRAJBER, R; MENDONÇA P; FERRARO JÚNIOR, L. A. - Artigo "Educação ambiental como política pública".publicado in Educação e Pesquisa, São Paulo, v. 31, n. 2, p. 285-299, mai/ago 2005.

Lei no 6.938 de 31 de agosto de 1981. Dispõe sobre a Política Nacional do Meio Ambiente. Disponível em htpp//www.planalto.gov.br. Acessado em 05/09/13 às $13 \mathrm{~h} 21 \mathrm{~min}$.

Decreto 1.306 de 9 de novembro 1994. Regulamenta o Fundo de Defesa dos Direitos Difusos, de que tratam os arts. 13 e 20 da Lei 7.347/85, seu conselho gestor e dá outras providências. Disponível em htpp/www.planalto.gov.br. Acessado em 05/09/13 às $13 \mathrm{~h} 28 \mathrm{~min}$.

Lei 7.347 de 24 de julho de 1985. Disciplina a ação civil pública de responsabilidade por danos causados ao meio ambiente, ao consumidor, a bens e direitos de valor artístico, estético, histórico, turístico e paisagístico e dá outras providências. Disponível em htpp//www.planalto.gov.br Acessado em 05/09/13 às 13h35min.

BARROS FERREIRA, R. Dano ambiental, < http://www.cenedcursos.com.br/upload/danoambiental.pdf > 05/09/13 ás 10h27min.

GUIMARÃES, C. Dano ambiental e sua reparação a luz do ordenamento jurídico, <http://www.webartigos.com/artigos/dano-ambiental-e-sua-reparacao-a-luz-do-

ordenamento-juridico/42237/\#ixzz2e1V7wRNo> Acessado em 05/09/13 as 09h35min. 